\title{
Communicating good care: a qualitative study of what people with urological cancer value in interactions with clinicians.
}

Skea ZC, Entwistle VA, MacLennan SJ, N'Dow J.

This is the authors' final version, post peer-review, of an article published in Eur $\mathrm{J}$ Oncol Nurs 2013; doi.org/10.1016/j.ejon.2013.09.009.The definitive version is available from http://www.sciencedirect.com

\section{Introduction}

Communication between health care providers and patients is essential for good quality care in several senses. Communication has many facets, can take diverse forms and serve multiple purposes. In the context of cancer care, communication with health care providers can be important to help meet patients' needs for information and other forms of support and can influence a range of cancer care outcomes both positively (e.g. Clayton et al., 2005; Fogarty et al., 1999; Kim et al., 2004; Neumann et al., 2007; Roberts et al., 2005; Schofield et al., 2003; Schneider et al., 2004) and negatively (Thorne et al., 2008), impacting for example on treatment adherence (Roberts et al., 2005; Schneider et al., 2004;), patient anxiety and depression (Fogarty et al., 1999; Schofield et al., 2003), and patient satisfaction (Kim et al., 2004). A small but growing body of evidence suggests that communication with health care providers can significantly affect the extent to which patients feel cared for, respected and involved (Burkitt-Wright et al., 2004; Fosbmder 1994; Kruijver 2000; Step et al., 2009; Thom 2000; Burkitt-Wright 2004;). These latter studies can be interpreted as suggesting that patients seem to value communication at least in part because of what it signals about healthcare providers' attitudes towards them, and thus about the interpersonal aspects of healthcare provider-patient relationships. They point to the significance of what has been referred to as health professionals 'seeing the person in the patient' (Goodrich and Cornwell, 2008) or treating patients 'as persons' (Entwistle and Watt, 2013). Good communication can therefore be valued both in its own right as a key element of patient-centred healthcare 
delivery (Epstein and Street, 2007; Street et al., 2009) and for its contributions to patients' health status and abilities to lead the kinds of lives they want to live (Entwistle et al., 2012). Despite this growing body of evidence, there remains a need to better understand how health care providers can act to facilitate or inhibit effective communication from the perspectives of patients and further research is needed to help focus communication research and teaching on what patients themselves value (Rosser and Kasperski, 2001).

Health services struggle to ensure consistently good communication between clinicians and patients, and a need to improve communication between health care providers and people affected by urological cancers has been recognised (National Institute for Clinical Excellence, 2002; Lee and Latini 2008). The National Institute for Health and Care Excellence (formerly National Institute for Clinical Excellence) emphasised the importance of ensuring that health care providers are "sensitive to potential problems with communication" which can lead to "unintended distress" amongst patients (National Institute for Clinical Excellence, 2002, p. 54 and p.57).

A particular lack of research relating to communication in the context of urological cancers has also been noted (National Institute for Clinical Excellence, 2002; Arora, 2008). Although more studies have been published recently, these relate almost exclusively to prostate cancer, and attend to only a limited number of communication issues, focusing particularly on information needs for treatment decision-making (Sinfield et al., 2009). Urological cancers $\underline{\text { can raise some particular issues for communication as there are many sensitivities around }}$ sexual, urinary and bowel function. It is therefore important that people with these cancers are included in studies of communication. Whilst this research is important, it leaves some potentially important aspects or implications of communication involving urological cancer patients poorly understood. 
This paper presents data from a qualitative study conducted among people with a urological cancer as part of an evaluation of a urological cancer care centre established in north-east Scotland in January 2008 (Skea et al., 2011). We examined what patients said about communication to identify what they appeared to value in their interactions with health care providers. We considered why particular aspects of communication mattered to them, and what the implications of these might be.

\section{Methods}

Patients were eligible to participate in this study if they had been diagnosed with a urological cancer and treated at the hospital where the Urological Cancer Care (UCAN) centre's main facilities are located (UCAN Centre, Aberdeen Royal Infirmary, UK). We sought to interview a diverse sample including men and women with different urological cancers.

We used two recruitment strategies. Both required patients to 'opt in' by making contact with a researcher. First, hospital staff used a health service database to identify eligible patients diagnosed with a urological cancer between 2007 and 2008. Patients were sent a study information leaflet and an invitation letter explaining that a researcher wanted to hear from patients about issues relating to their care and treatment as well as their views about communication with clinicians. Second, patients who attended a meeting at the urological cancer centre for those who were registered as peer supporters for newly diagnosed patients were informed of the study and asked to indicate their willingness to be contacted by the researcher to take part in an interview. 
72 people were approached by hospital staff: 22 volunteered contact details and 19 were interviewed. 14 people volunteered contact details after attending the peer supporter meeting and 7 were interviewed. In purposively sampling from those who volunteered contact details, attempts were made to include both men and women and to ensure people with different cancer types were represented.

The total sample of 26 included 20 men and 6 women, aged from 37 to 80 years, who had been diagnosed with cancers of the prostate (6), bladder (6: 2 female; 4 male), kidney (8: 4 female; 4 male) or testes (6). All were white British and lived in Aberdeen city, Aberdeenshire, Moray or Orkney.

We used telephone interviews to minimise participant burden and to avoid excluding people who lived in remote areas. The study was approved by the North of Scotland Research Ethics Committee. All participants gave written consent before participating in a telephone interview.

At the start of the interviews, participants were encouraged to provide a narrative account of their cancer journey - in other words to tell how they came to discover they had cancer and to discuss what had happened to them since that time. They were then asked about their reactions to their diagnosis, information and support needs (around diagnosis and subsequently), interactions with health professionals, and views about the care they experienced. Interviews lasted 40-80 minutes and were audio-recorded and transcribed.

Transcripts were analysed thematically using an established interpretive approach (Ritchie and Spencer, 1994). Following initial familiarisation with interview transcripts, the authors 
developed a thematic coding framework based on discussions about both a priori questions and issues identified as emerging from the interview data. Initial codes (text labels) from this framework (including codes relating to communication with health professionals) were then systematically applied to the transcript data. NVivo8 text management software was used to mark specific pieces of interview data that were identified as corresponding to the thematic index codes. More generally, NVivo 8 was also used to help organise the data to facilitate further analytic consideration and interpretation.

In the findings below, the individual patients who were the source of particular quotations are identified by pseudonyms.

\section{Results}

Everyone who was interviewed mentioned examples of communication with health care staff, including nurses, in their evaluative reflections on the service. Patients often commented positively about communication, although some reflected negatively on specific encounters.

Patients' reasons for valuing aspects of communication varied, but our analysis of these reasons led us to recognise that they could mostly be understood in terms of communication having implications for the ways patients felt related to as people. We present the study findings under three main themes that are interlinked and can all be associated with the notion of patient- or person- centred care. These are perceptions that health care staff had 1) treated the patient as someone of value in themselves, someone worthy of care; 2) recognised and responded to patients' individual needs and unique identities; and 3) recognised and supported patients' autonomy_and/or agency. Within each theme, we illustrate the kinds of communicative behaviours or ways of relating that were associated 
(positively or negatively) with the evaluative perceptions of what health care staff had done or achieved, and how these behaviours had impacted on patients' experiences.

\section{1) Being treated as someone who matters and is worthy of care}

Several patients commented positively on situations in which they felt that health care staff interacted with them "as a person" and not simply "a number" (Albert, Bladder cancer), and as a person who was worthy of care rather than as someone staff could not be bothered to help. Their accounts suggest that staff could demonstrate to patients that they mattered and were worth caring for in various ways including, for example, by

i) Interacting warmly and signalling personal recognition by using and remembering the patient's name;

"I find the staff pretty friendly actually, especially in ward [number] where they do the testing, they just say oh you're back Mr [name], I say yes, it's like being on first name terms with some of them!... Oh yes they get to know you, they do get to know you." (Albert, Bladder cancer).

"What a nice woman that was [cancer support nurse]..when I woke up after my first operation, when I opened my eyes she was sitting at my bed holding my hand, now what do you think of that one, that's a good one... She was a big, big advantage to me...It's the same when I went down to the high dependency unit, as you know you have your own nurse, there was a nurse in there, if I sneezed she was there with a tissue, you know she was as good as that as I say she put my mind at rest two or three times ..." (William, Bladder cancer)

ii) Anticipating and attending to care needs;

"I thought [consultant] was a superb bloke and he said to me once "look, if there's anything at all I want phone up and if I' $m$ not available you leave a message with my secretary... and she will get hold of me, that's the main man...they were attentive, they seemed to care, nothing was a bother" (Craig, Kidney cancer).

Conversely, perceived lack of care and of needed practical support appeared to cause disappointment and frustration. Although some patients reported managing to secure help 
from family, friends or other patients, they nonetheless found it problematic when staff were insufficiently attentive;

"..after-care after my operation there wasn't care as far as I was concerned! The care in the hospital was not good after the operation....Well it was just nobody seemed to come near you... I wasn't happy with the care at all... there wasn't a lot of care on the ward... and even getting showered, there seemed to be sort of favourite patients!..you were finding that you were needing help for something and they were standing outside the ward having a chat, things like that and that's no good.". (Mary, Kidney cancer).

iii) Following through on commitments;

Honouring commitments was also an important indicator of good care to several patients.

This became apparent during discussions of instances where health care providers had apparently failed to honour commitments such as promising to keep patients informed of test results or forthcoming hospital appointments, or to provide practical assistance such as help with changing catheters and dressings:

"..well just before [an operation to remove a testicle]...he [consultant] said to me that he would write to me as soon as he got the results, to save me waiting... he went off on holiday and the information was left on someone's desk and it took me over three and a half weeks before I found out whether it definitely was [cancer] and what type of cancer it was...I was a bit annoyed about it really..." (Neil, Testicular cancer).

iv)Being honest about prognoses and safety issues but without destroying hope;

Patients discussed valuing their health care provider having been honest, 'straight' and frank with them during discussions about their cancer and/or its treatment. The manner of presentation of this information seemed important, and patients valued a sense that information was not being deliberately withheld from them. A perception that their health care provider was being 'straight' with them with regard to treatment and prognoses information (without destroying hope) seemed to enhance trust and confidence in their 
clinician's level of expertise:

"...he [consultant] was absolutely brilliant...To be honest, he was honest and if you wanted to know anything and asked him he would tell you, I mean he didn't try and dress it up any different, he would tell it to you the way that it actually was, and the same with all of them." (Neil, Testicular cancer).

However, communication behaviours or styles were interpreted in different ways by different people and despite some people stating that they valued health care providers who did not "dress [things] up," others described situations in which they believed they had been too direct or even alarmist in the way that they communicated opinions about, for example, disease prognosis status and/or recommendations about treatments. This had resulted in increased anxiety for themselves and family members. Sometimes this direct approach or style of communicating was contrasted with other health care providers they had encountered who they had perceived as having been more reassuring and hopeful:

"I didn't take it too well [being diagnosed for a $2^{\text {nd }}$ time with testicular cancer]. The fact it came back from the biopsy after the operation that it was a teratoma tumour and the news was given to me by my GP and he didn't give me a lot of hope to say the least... went to see [consultant] and [consultant] spoke to me and basically gave me a big boost in confidence... He [consultant] basically made her [wife] feel a lot better about it and that's what I liked about [consultant]... He just got that charisma and that's what I liked about the guy..." (Simon,Testicular cancer).

"..he said we've got to remove your bladder because there is no more we can ...I felt terrible ...I said is that the only solution and he said I'm afraid so and that was it...I started calling him 'Dr Doom'... Maybe he was just trying to prepare me, I don't have any idea but I mean all the other doctors seem quite positive.... for that Dr [name] to say we've got to remove your bladder, that just finished me, you know, I was really, really worried. I was really worried." (Lynn, Bladder cancer).

Patients also seemed to value staff that had admitted mistakes and apologised after apparent errors in care. For some, an apology and an indication that 'lessons had been learnt' helped to create a perception of caring: 
"it turned out there was a small piece of kidney had been left from the initial operation ... he [consultant] was really sorry about what had transpired ... and he said to me "if there's any solace to you, we've changed the way we actually do that operation" (Craig, Kidney cancer ).

Conversely, perceptions that health care providers had not disclosed or apologised for apparent mistakes created an impression of a lack of caring or respect, with one patient being frustrated because of a lack of "an explanation for what went wrong" during an operation and commenting that in his opinion his care could have been more "humanely done" (Alan, Prostate Cancer).

\section{2) Being recognised and responded to as a unique individual with a particular social context}

Patients spoke positively about occasions when they perceived that health care staff were attentive to their (and family members) particular needs in ways that suggested they were willing to be flexible for them, to tailor care to suit their circumstances or make special arrangements. Participants valued the reassurance this attentiveness gave them and their family members that help would be available when it was needed. For example:

"I used to bypass the system slightly and I used to just nip up to [ward] and say look, I need a bladder washout. That's when the catheter's blocked. I mean I don't live too far from [hospital] and it was very reassuring for me and for my wife to know that when things went wrong - which they did on several occasions - she could drive me down to [hospital] and I could just walk into the ward and say I need this fixed. I never had a negative response at any time. ... okay we'll fix it for you. You know? Which is probably not the right thing to do but it suited me and it certainly took a load off my wife..."(Geoff, Prostate cancer).

"I think it's just the way that he [consultant] speaks to you and because my wife has been with me through all of this, she comes to all the clinic meetings and he speaks to both of us, you know, it's not just he's speaking to myself and the wife is in the background cause she's very concerned as well what's going on." (Simon, Testicular cancer). 
Several people also discussed instances whereby staff had apparently 'tailored' aspects of the health care system to accommodate individual circumstances and preferences (e.g. by allowing a patient to stay at home between chemotherapy sessions and for apparently trying to fast track patients through appointment systems) resulting in some feeling that they had received 'special' treatment. For example:

"my white blood cell count was below the level that they could administer the chemotherapy and it was delayed by a few days, which basically meant instead of starting off on the Monday, it started off on the Wednesday and finished on a Sunday which I had to go up to ward 17 to have ... But because I had quite a good relationship with [consultant] and I says to him "I only stay up the road is there a possibility that I could go home and come in first thing in the morning" and he says "since it's you!" (Simon, Testicular cancer).

"...the young doctor that first gave me the cystoscopy, he was really nice...And then he took me through to the wee changing room place... and of course the tears were coming down and I was wiping my face with my jacket, I think the sleeve of my jacket. I remember him saying okay I'll put it in as urgent and I thought well it was really nice that they sort of took, that he saw that I was upset obviously and I knew that I wasn't going to have to wait long." (Elizabeth, Bladder cancer).

If staff members appeared not to acknowledge, for example, significant features of their particular (including social) circumstances, they could appear to be unaccommodating of their legitimate care needs:

"Well some of them are quite good and some of them just I suppose they must cut themselves off, I mean they can't be, what gets me though, sometimes their attitude, I mean I could go into hospital for three days, have an anaesthetic, feel fine and they'll say okay, you can go home. There's no reason, there's no asking is there somebody [at home] you know [gets upset] now that gets to me, I think they should be asking..." (Lynn, Bladder cancer).

\section{3) Experiencing support for autonomy and/or agency}

Several patients discussed valuing the relationship $\underline{s}$ and partnership $\underline{\underline{s}}$ that they felt they had developed with particular staff because of the ways these had enabled them to understand and contribute to discussions about their condition and care. Their comments suggest that 
when health care staff enter willingly into conversations and are generous in information provision, patients can feel more confident to ask questions and, to-engage in two-way discussions about their care and treatment:

".... I would even say to the likes of [consultant], I says "I was looking at the haematology results and what do you think of that?" and it's just the sort of conversation we had and he wouldn't be obnoxious he would speak to me about it ... It was just good to have that relationship." (Simon, Testicular cancer).

“...you just know when somebody speaks, 'alright they're OK!', he was just easy to speak to, makes you relaxed... basically if [consultant] had come round and he'd had the results with him I'd say "can I get a copy of the results" and he says "yeah, you can have this one" [laughter]... I really really respect [1 ${ }^{\text {st }}$ consultant] for what he's done for me." (Nick, Testicular cancer).

Communication that enables patients to understand their condition and their healthcare options, and to feel that they are respected and trusted as partners in their care, provides important underpinnings for the exercise of autonomy and agency. Communication that does not enable patients in these ways can positively undermine not only the scope that patients have to act to contribute to their care, but also the self-respect and self-trust that are needed for their exercise of autonomy, in healthcare settings and beyond (McLeod, 2002, Entwistle et al 2010).

\section{Discussion}

We examined views about communication amongst urological cancer patients, seeking to generate insight into how patients describe and value features of communication with health care staff, and to consider the implications of this for their experiences of care. Participants commented positively on features of communication that could be associated with staff treating them as worthy of care, responding to their individual circumstances and identities, and supporting their autonomy/agency through the development of enabling relationships and partnerships. 
Our findings are consistent with an emerging body of research (in other cancer and noncancer settings) which suggest that patients notice and value aspects of communication that impact on their feeling cared for and respected (Burkitt-Wright et al., 2004; Entwistle et al., 2008; Epstein, 2006; Quirk et al., 2008; Salmon et al., 2009; Thom and Campbell, 1997; Ziebland et al., 2010). Relational communication has been described in the literature as "those identifiable verbal and nonverbal behaviours that carry message value about the type of relationship the communicators share" Step et al., 2009). In our study with urological cancer patients, good relational communication (from the perceptions of these patients) involved both those verbal and nonverbal behaviours which indicated to patients that health care providers had a) treated them as someone of value in themselves; b) recognised and responded to their individual identity and c) recognised and supported their autonomy/agency. Consistent with several key accounts of patient centred medicine (Balint, 1955; Stewart, 1955; Mead and Bower, 2000; Entwistle and Watt, 2013), whilst arguably these behaviours should be regarded as a desirable in their own right, they are also potentially important for influencing the health status outcomes of care in both direct and indirect ways. A recent monograph produced on behalf of the National Cancer Institiute postulated that there are at least seven 'pathways' through which health can be improved by health care provider-patient communication - access to care; increased patient knowledge and shared understanding; enhancing therapeutic alliances (among providers, patient, and family); enhancing emotional self-management; activating social support and advocacy resources; increasing the quality of medical decisions; and enabling patient agency (Epstein and Street, 2007; Street et al., 2009). 
Our methods have some limitations that need to be taken into account when interpreting our findings. Firstly, we collected data from patients' perspectives only (we did not record consultations and did not interview health care staff). Secondly, we asked patients to give retrospective accounts. It is possible that their recollections could have been influenced by their intervening experiences (Entwistle et al., 2002). However, we were trying to gauge patients' perceptions of what happened in the past (irrespective of whether these perceptions were 'correct' or 'justified'). Although perceptions may change over time, this does not render them unimportant or wrong. Despite its limitations, we believe that our study provides useful data which supports and adds to an emerging body of research (in both cancer and non-cancer contexts) attending to the aspects or implications of communication that matter to patients. Our study has also provided novel data about an important but under researched aspect of urological cancer.

In the context of urological cancer, most research relating to communication to date has focused on the informational needs and treatment preferences of newly diagnosed patients (Sinfield et al., 2008; Feldman-Stewart et al., 2008. Whilst such research is important (and some patients in our study did indeed discuss the issue of information provision), the relational function of communication in urological cancer care (and in other cancer contexts) has been largely neglected. In this study, we have demonstrated that patients seem to value communication at least in part because of what it signals about health care providers' attitudes towards them, and thus about the interpersonal aspects of these relationships. The relational implications of features of communication are important for respect for autonomy (Entwistle et al., 2010) and for patients' abilities to contribute to their care (McLeod, 2002). They may contribute to patients' subjective wellbeing both by facilitating their participation in health care and possibly more directly. 
The manner in which a particular communication behaviour might or might not lead to improved health requires further research (Street et al., 2009). Furthermore, health care outcomes, especially those related to cancer and chronic illness, are less likely to be influenced by a single one-off provider-patient encounter, and more by the cumulative effect of the patient's communication over a period of time with their clinicians, nurse, others on the health care team, friends and family. However, health care staff involved in the care of urological cancer (and other cancer) patients need to recognise the potential impact of their own relational communication behaviours on the ways patients feel related to as people behaviours (or a set of underlying abilities) which are not usually emphasised in training (Burkitt-Wright et al., 2004; Back et al., 2005) but which can indicate a caring attitude to a patient which can in turn enhance trust, provide reassurance and facilitate appropriate patient contributions to care. Patients in our study noticed aspects of their health care providers' overall 'style' and this included valuing positively those who appeared attentive and responsive to individual needs for care, and also those who were perceived to be sensitive to their needs in terms of how information was communicated. Patients reacted positively when health care staff were perceived to have honoured commitments and also when they had acknowledged and apologised if an aspect of patient care had not gone to plan. These behaviours do not necessarily require a complicated approach to learning specific communication skills but rather involve a set of behaviours which are indicative of genuine caring and which help patients and their families feel reassured and supported.

Efforts to improve health care provider-patient communication and promote effective partnership between the two parties should attend not only to the provision of information about the condition and its management but also to the broader aspects of the way health care providers interact and the implications of these for how people feel in terms of being 
cared about and respected, appropriately responded to as individuals, and enabled to participate in discussions about matters affecting them.

\section{Funding}

This research was supported by a grant from Grampian NHS Endowment Committee. The views expressed here are the authors' and do not necessarily reflect those of the funding bodies or any other organisation.

\section{Conflict of interest}

None declared

\section{Acknowledgements}

We would like to thank the patients who agreed to participate in this study for their time and valuable contributions.

\section{References}

Arora, NK., 2008. Advancing research on cancer communication. Patient Education and Counseling, 70, 3, 301-302.

Back, AL., Arnold, RM., Baile, WF., Tulsky, JA., Fryer-Edwards, K., 2005. Approaching difficult communication tasks in oncology. CA: A Cancer Journal for Clinicians 55,164-77.

Balint, M., 1955. The doctor, his patient and the illness. Lancet 1,318.

Burkitt-Wright, E., Holcombe, C., Salmon, P., 2004. Doctors' communication of trust, care and respect in breast cancer: qualitative study. British Medical Journal 328(7444),864.

Clayton, JM., Butow, PN., Arnold, RM., Tattersall, MHN., 2005. Fostering coping and nurturing hope when discussing the future with terminally ill cancer patients and their caregivers. Cancer103, 1965-1975.

Entwistle, V., Tritter, J., Calnan ,M., 2002. Researching experiences of cancer: the importance of methodology. European Journal of Cancer Care 11,232- 237.

Entwistle, V., Prior, M., Skea, Z., Francis, J., 2008. Involvement in treatment decision-making: a qualitative investigation of its meaning to people with diabetes. Social Science \& Medicine 66(2),362-375. 
Entwistle, VA., Carter, SM., Cribb,A., McCafferty, K., 2010. Supporting patient autonomy: the importance of clinician-patient relationships. Journal of General Internal Medicine 25 (7),741-5.

Entwistle, VA., Firnigl, D., Ryan, M., Francis, J., Kinghorn P., 2012. Which experiences of healthcare delivery matter to service users and why? A critical interpretive synthesis and conceptual map. Journal of Health Services Research and Policy, 17(2): 70-78. doi: 10.1258/jhsrp.2011.011029..

Entwistle V.A., Watt I.S., 2013. A capabilities approach to person-centered care: response to Open Peer Commentaries. American Journal of Bioethics, 13(8):29-39.

Epstein, RM., 2006. Making communication research matter: What do patients notice, what do patients want, and what do patients need? Patient Education Counseling 60,272-278.

Epstein, RM., Street Jr, RL., 2007. Patient-centered communication in cancer care: promoting healing and reducing suffering. Bethesda, MD: National cancer Institute [NIH Publication No.07-6225].

Feldman-Stewart, D., Brennenstuhl, S., Brundage, MD., 2008. The information needed by Canadian early-stage prostate cancer patients for decision-making: Stable over a decade. Patient Education and Counseling73, 437-442.

Fogarty, LA., Curbow, BA., Wingard, JR., McDonnell, K., Somerfield, MR., 1999. Can 40 seconds of compassion reduce patient anxiety? Journal of Clinical Oncology 17, 371-9.

Fosbmder, D., 1994. Patient perceptions of nursing care: an emerging theory of interpersonal competence. Journal of Advanced Nursing 20, 1085-1093.

Goodrich, J., Cornwell, J., 2008. Seeing the Person in the Patient. London: The King's Fund.

Kim, S., Kaplowitz, S., Johnston, M., 2004. The effects of physician empathy on patient satisfaction and compliance. Evaluation and the Health Professions 27, 237-51.

Kruijver, IPM., Kerkstra, A., Bensing, JM. .,van de Wiel, HBM., 2000.Nurse-Patient Communication in Cancer Care: a review of the literature. Cancer Nursing 23, 20-31.Lee, C., Latini, D., 2008. Urinary diversion: evidence-based outcomes assessment and integration into patient decision-making. British Journal of Urology International, 102 (pt B), 1326-33.

McLeod, C., 2002. Self trust and reproductive autonomy. Cambridge MA: MIT Press.

Mead, N., Bower, P., 2000. Patient-centredness: a conceptual framework and review of the empirical literature. Social Science Medicine 51,1087-1100.

National Institute for Clinical Excellence (NICE)., 2002. Improving outcomes in urological cancers. Guidance on Cancer Services, 54-57.

Neumann, M.,Wirtz, M., Bollschweiler, E., Mercer, S., Warm, M., Wolf, J., Pfaff, H., 2007. Determinants and patient-reported long-term outcomes of physician empathy in oncology: A structural equation modelling approach. Patient Education Counseling 69,63-75. 
Quirk, M., Mazor, K., Haley, HL., Philbin, M., Fischer, M., Sullivan, K., Hatem, D., 2008. How patients perceive a doctor's caring attitude. Patient Education and Counseling 72,359366.

Ritchie, J., Spencer, L., 1994. Qualitative data analysis for applied research. In Bryman ,A., Burgess, RG., (Eds.), Analysing qualitative data. London, Routledge, 173-94.

Roberts, C., Benjamin, H., Chen, L., Gavigan, M., Gesme, DH., McCarthy, P., Samuels, RJ., Baile, WF., 2005. Assessing communication between oncology professionals and their patients. Journal of Cancer Education 20,113-8.

Salmon, P., Humphris, GM., Ring, A., Davies, JC., Dowrick, CF., 2009. Primary care consultations about medically unexplained symptoms: how do patients indicate what they want. Journal of General Internal Medicine 24(4),450-6.

Schneider, J., Kaplan, SH., Greenfield, S., Li, W., Wilson, IB., 2004. Better physician-patient relationships are associated with higher reported adherence to antiretroviral therapy in patients with HIV infection. Journal of General Internal Medicine 19,1096-103.

Schofield, PE., Butow, PN., Thompson, JF., Tattersall, MHN., Beeney, LJ., Dunn., SM 2003. Psychological responses of patients receiving a diagnosis of cancer. Annals of Oncology 14,48-56.

Sinfield, P., Baker, R., Agarwal, S., Tarrant, C., 2008. Patient-centred care: what are the experiences of prostate cancer patients and their partners? Patient Education and Counseling 73,91-96.

Sinfield, P., Baker, R., Camosso-Stefinovic, J., Colman, AM., Tarrant, C., Mellon, JK., Steward W., Kockelbergh, R., Agarwal, S., 2009. Men's and carers' experiences of care for prostate cancer: a narrative literature review. Health Expectations, 12, 301-312.

Skea, ZC., MacLennan, S., Entwistle, V., N'Dow, JMO., 2011. Enabling mutual helping?: Examining variable needs for facilitated peer support'. Patient Education and Counseling 85(2), e120-e125.

Step, MM., Rose, JH., Albert, JM., Cheruvu, VK., Siminoff, LA., 2009. Modeling patientcentered communication: oncologist relational communication and patient communication involvement in breast cancer adjuvant therapy decision-making. Patient Education and Counseling 77,369-78.

Stewart, MA., 1955. Effective physician-patient communication and health outcomes: a review. Canadian Medical Association Journal 152,1423-33.

Street, RL., Makoul, G., Arora, NK., Epstein, RM., 2009. How does communication heal? Pathways linking clinician-patient communication to health outcomes. Patient Education and Counseling 74, 295-301.

Thom, DH., Campbell, B., 1997. Patient- physician trust: an exploratory study. Journal of Family Practice 44(2), 169-176. 
Thom, DH., 2000. Training physicians to increase patient trust. Journal of Evaluation in Clinical Practice 6, 245-253.

Thorne, SE., Hislop,TG., Armstrong, EA., Oglov, V., 2008.Cancer care communication: The power to harm and the power to heal? Patient Education and Counseling 71,34-4.

Ziebland, S., Evans, J., Toynbee, P., 2010. Exceptionally good? Positive experiences of NHS care and treatment surprises lymphoma patients: a qualitative interview study. Health Expectations 14(1),21-8. 